\title{
Utilizing technologies of fog computing in educational loT systems: privacy, security, and agility perspective
}

\author{
Amr Adel ${ }^{*}$ D
}

\author{
*Correspondence: \\ amra@whitecliffe.ac.nz \\ Whitecliffe College \\ of Technology \\ and Innovation, Auckland, \\ New Zealand
}

\begin{abstract}
Fog computing architecture is referred to the architecture that is distributed over the geographical area. This architectural arrangement mainly focuses on physical and logical network elements, and software for the purpose of implementing proper network. Fog computing architecture allows the users to have a flexible communication and also ensures that the storage services are maintained efficiently for the purpose of managing the data. However, it has been observed that in the field of education fog computing architecture has gained huge importance due to its real time application feature. The main objective of the survey is to develop a systematic literature review for the technology of fog computing in the education loT system. The survey will also focus on evaluating the essential factors that has a crucial role in the fields of education as well as investigating the limitation and findings associated with the fog computing technologies in educational systems from the perspective of privacy, security, and agility.
\end{abstract}

Keywords: Fog computing, Edge computing, Education system, loT, Virtualization

\section{Introduction}

Advancement in the field of sciences have given rise to numerous technologies which has changed the ways in which world used to be. Starting from the business sectors, to the health care, transportation, education along with general households have gone through an enhancement and metamorphism [1]. Mentioning of the technologies I come through the technologies like Artificial intelligence, big data analytics, cloud computing, augmented and virtual reality has played remarkable role in enhancement of the operations and processes in various sectors and also in inventing new ways to develop various aspects of different systems like the health care, education, administration, decision making and many more. One of such technology is internet of things or IoT [2]. Internet of things have gained a lot of recognition for the range of services that it provides to the users of the technology. This is a combination of numerous other technologies working in synchronization to provide an excellent service to the mankind. They are capable of generating signals along with capturing them, this helps them in gathering data which is very essential for the evaluation and development of the system. Any structured and

(2) The Author(s) 2020 This article is licensed under a Creative Commons Attribution 4.0 International License, which permits use, sharing adaptation, distribution and reproduction in any medium or format, as long as you give appropriate credit to the original author(s) and the source, provide a link to the Creative Commons licence, and indicate if changes were made. The images or other third party material in this article are included in the article's Creative Commons licence, unless indicated otherwise in a credit line to the material. If material is not included in the article's Creative Commons licence and your intended use is not permitted by statutory regulation or exceeds the permitted use, you will need to obtain permission directly from the copyright holder. To view a copy of this licence, visit http://creativeco mmons.org/licenses/by/4.0/. 
unstructured data is very useful for enhancement of the process and when it comes to the system of education, this is very important. There are rich variety of technologies which are covered by the internet of things and they are-industrial internet of things (IIoT, internet of services, customer IoT, Industry 4.0, and many more [3]. However, these technologies cannot completely function on themselves without the assistance of the technologies like the edge computing, cloud computing, big data analytics, machine learning and a few more and all this is for the gathering and processing the data such that they can be used for betterment of the operations.

In this aspect, another technology is regarded and that is fog computing. This is a branch or an extension of the cloud computing technology [4]. This technology makes the cloud technology most suitable for usage on the internet of things. One of the major benefits of the technology is its ability to handle applications which requires the realtime interactions. Fog is a layer of distributed network which makes use of the public infrastructure as a service, which helps in the development of high level endpoints for the data and the IoT devices are created at the end of the network [5]. The fog computing acts a media that provides the missing link between the requirements of the data that is needed to push it into the cloud and the aspects which can be analyzed locally [6].

The flexibility of the technology makes it useful for the usage in the education system as well. The system of the education deals with a whole lot of data and analysis of the data is very important when it comes to the evaluation of the data and identifying the performances of an individual [7]. Internet of things offers a wide range of services with computational facilities. This helps in improving the way storage capabilities are enhanced in different fields and also helps in improving the business processes. IoT helps in staying connected with the objects for the purpose of sharing and exchanging the data [8]. With the evolution of technologies, it has been observed that the control over the different applications has reduced to great extent and thus there is a need to manage the system flow. Cloud computing has gained huge importance in the fields of education [9]. The fog computing concept was identified with the purpose of determining the limitations associated that are faced with the use of cloud computing. The use of fog computing helps in shifting the capabilities of cloud towards the end user and offers a better storage capability with enhanced computation features. The main reason behind using fog computing is that it offers better communication, enhances privacy, offers better security, and also increases the network bandwidth so that it becomes easy to match the latency sensitive $[10,11]$. The concept of fog computing helps in ensuring that the application designed has the capacity to satisfy the needs of the education IoT system.

It has been observed that the performance offered with the education system and the way lessons are taught towards the student may get hampered due to low latency and this will eventually lead to hampering the data shared. IoT helps in providing a better platform for the students so that they can easily access the materials from the communication channel [12]. Education application tends to store huge data related to the students, staffs, and their associated document. Hence there is a need to manage proper storage so that the data can be organized properly [13]. In the fields of education there are several data stored and retrieved for daily activities. Thus, it becomes essential to integrate properly the responses that are associated with the IoT system. The fog computing infrastructure involves connecting different fog nodes together for the purpose of 
improving the scalability, elasticity, and the redundancy [14]. After analyzing the wide range of features offered with the fog computing it can be stated that, with the use of fog computing in the educational field it will become easy to offer the facilities towards the students.

In majority of the countries across the world, the traditional education system is followed. However, the non-digitized education system followed by the esteemed institution are often subjected to the major discrepancies in learning process. The data and the information that are shared by the students are often at stake due to the absence of back up and security [15]. The amount of the data that is collected by the education system is huge and is often happened to contain numerous information like the crucial educational details, financial and account details, transaction ids and many more [16]. The data are not only vulnerable to the external sources, they are also vulnerable to the internal sources as well. This is one of the major reasons behind the research and the introduction of the new technologies in the system. These developing and developed technologies can provide an excellent solution to the existing problem related to the loss, damage, and manipulation of the data in the system of education. Not only that, the advent of the technologies like the fog computing and IoT and the way they have proven beneficial in the other phases of the industry, the research must be conducted based upon the usage of the technology in the field of education such that the students, teachers and administration can be helped in a positive way.

The main aim of the study is to develop a systematic literature review on fog computing in the fields of education so that it becomes easy to analyze the architecture. The literature review will focus on identifying the problems and challenges that are faced with the use of IoT systems [17]. The second objective of the paper is evaluating the performance that is offered with the use of fog computing in education IoT system. The paper is divided into different sections that include discussing the methodology behind the research paper, related paper discussion, discussing the role of fog computing in the education application, identifying the limitations, providing proper recommendations and last focus will be on explaining the conclusion [18]. The paper will focus on evaluating the different concepts that are related with managing the education related data effectively with the use of proper fog computing implementation.

The below structure is designed for the purpose of understanding the paper objective more clearly. Section "introduction" provides an exploratory channel to discuss the main factors that are associated with the emerging technologies of fog computing. The introduction section shares some details regarding the components that are going to be discussed within this paper. Section "research methodology" is designed for the purpose of stating the most suitable approach for uncovering the dynamics associated with the fog technologies in IoT educational systems. Section "research questions" is identified in this section. The research questions are meant to be answered through this paper. Inclusion and exclusions: The facts that are considered and are not considered in the paper are discussed in this part of the paper. Study selection: The study selection states influences which are considered crucial for developing the paper. Section "Fog computing in education IoT systems" is aimed to ensure that the fog computing has been discussed properly for providing a better way of demonstrating the importance in education IoT systems. Section "related works" includes identifying and evaluating the related work 
associated with the fog computing in education IoT system. Section "limitations" demonstrates obstructions associated with the paper in this part of the research analysis. Section "discussion and open issues" states the issues and challenges that are encountered while utilizing the technology of fog computing in this part of the paper. Section "recommendations" provides appropriate recommendations for overcoming the challenges along with learned lessons that are learned through this paper.

\section{Motivation}

1. The main reason for conducting this research is studying the current education system. The contemporary education system fails to maintain the data with effectiveness and efficiency. The current education system, making usage if the traditional data does not ensure the security of the data, making the information of the students and the administration vulnerable to the external threats along with the internal threats of the organization. This is one of the motivation factors for taking up the research.

2. As the current system of the education in most of the part of the world makes use of the legacy systems with the manual databases that has to be updated, no back up is generated automatically. If the data is lost or manipulated by any mean, there are no such ways in which they can be retrieved. This is another factor which has motivated the researcher to conduct the research to identify the usage of the Fog Computing technology for the storage and the management of the data.

3. Last but not the least is the fact that both the internet of things and the fog computing are emerging technologies, and researcher finds it is the best way in which these technologies can be understood in depth and the ways in which they can be used for enhancement of the education along with the entire system of education.

\section{Research questions}

1. What aspect of the current system of education makes the introduction of the fog computing and IoT technologies an obvious factor?

2. What are some of the major benefits of the Internet of Things and how the technology can serve for the betterment of the system of education?

3. How can fog computing technologies be utilized in educational IoT systems to provide high level of accuracy, privacy, security, and agility?

\section{Research methodology}

Fog computing is considered as the most efficient way of improving the efficiency and also ensures that the amount of data needs to be transported are provided with a better storage [19]. The major steps that are associated with planning the process for fog computing implementation in the fields of education application are as follows: introducing fog computing and IoT technologies in education, identifying the major benefits of fog computing along with IoT in education, illustrating the reflection of fog computing and IoT technologies in education in terms of implementation and integration process, 
identifying the requirements that are essential for managing the information related to education, defining and investigate the gaps that lies in the researches, improving the procedure for performing systematic literature review on fog computing in the fields of education system [20]. The main objective is to explore the importance of Fog computing in Education IoT system. The information needed for managing the computing process should have the potential to ensure that the research have been executed properly. This guideline will go through three major processes: planning review, conducting review, and documenting review. The major stages of the guideline are illustrated in Fig. 1.

Planning review is concerning about identifying the requirements and needs for utilizing the fog computing into educational IoT systems. Based on that, research questions have been articulated in a way that helps finding credible information and clear guidelines on how to utilize and develop fog computing technologies into education by developing and validating reliable resources that provide trusted information. Conducting review is the process which has been initiated for selecting the relevant studies from reliable sources to help in extracting the required data in terms of performance, privacy, security, and agility. Once required data has been selected for extraction, synthesizing of data begins for drawing a clear picture of what should be made for the utilization process of fog computing technologies into educational IoT systems. At the end, documenting review is running in a way that materializes all useful data gathered from credible sources for further observations, examinations, and analysis. This step would help in formulating the results in a well-descriptive form.

\section{Inclusion}

In order to conduct the research certain articles and educational journals have been consulted. The reputed and most cited educational journals by, Web of Science (WoS), ScienceDirect, Scopus, and IEEE Xplore Digital Library. All of them are mainly inclined to

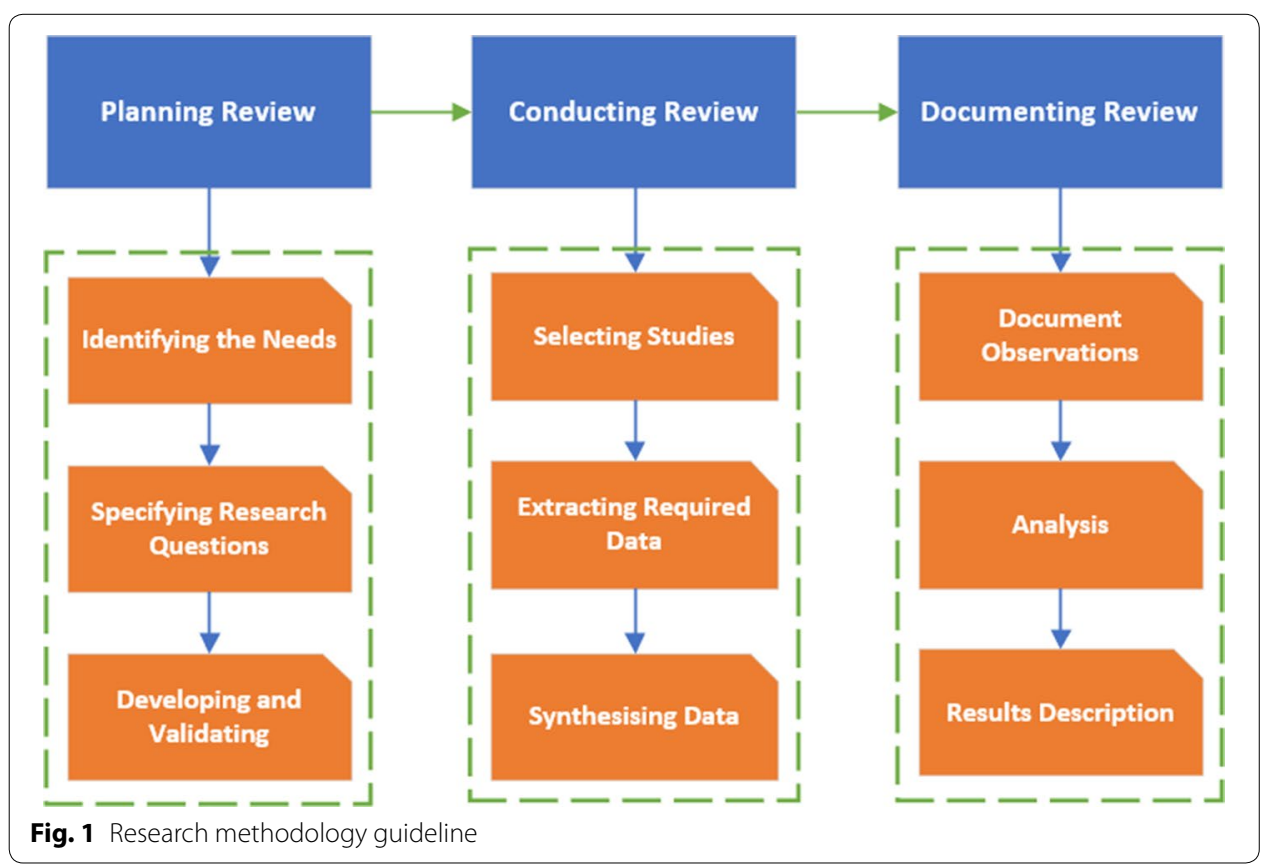


the topic of discussion and discussions on the framework of the cloud computing, usage of IoT, Fog computing, their benefits, and numerous others. With the appropriate evaluation of the papers, the research becomes easier and drawing the findings of the research becomes easier as well.

\section{Exclusion}

The fog computing role in education is one of the main concerns. However, in order to carry out the research no use of books, non-English articles and other topics related articles have been done. These components are avoided for doing the paper completely. The use of non-English and non-related articles is not considered for this paper.

\section{Study selection}

In order to carry out the studies it becomes essential to review proper study area that will be capable of managing the data. Before reviewing any article, it is important to ensure that all the concepts related to fog computing are being analyzed properly [21]. It is important to ensure that all the related articles are executed form the list so that it becomes easy to explore the new knowledge areas related to fog computing in the education IoT system.

\section{Fog computing architecture}

For any IoT system which has a fog layer, the proposed architecture must either be application agnostic or application specific. The architecture can be broadly classified into three main strata, things layers, fog layer and cloud layer [22]. The Things layer is also referred to as the perception layer and can be regarded as a point where the IoT structure starts with the generation and collection of data [23]. It has network Things like, Sensors objects and devices which has communication protocols allowing transmission of the generated data through nodes to the fog or IoT network as shown in Fig. 1.

The Fog layer is supposed to have several decentralised nodes present in each location. This layer has the task of handling all the networks and the data received [24]. The primary refining computation and processing of data is done here and after that, the IoT applications are enhanced by controlling the data transmission to the cloud layer and reducing the request-response time taken for an IoT application. Finally, the cloud layer or the data centre's layer is regarded as IoT architecture's topmost layer. This layer has the function of allowing network access, conveniently and properly across all the shared resources in the IoT network. The storage and services areas of the IoT network requires heavy duty and is performed by the cloud layer [25].

As shown in Fig. 2, the fog nodes have been placed in the middle of layers between the cloud and IoT services in the order. The reason why fog nodes are in the middle is to support processing, securing, and storing IoT devices engaged and provided in the cloud. During this process, transaction analytics is performing dimension reduction, cleaning data, conduct automatic handling in order to process the data over the cloud. Due to the lack of sufficient computing power in the IoT nodes, fog computing can offer some intelligent features to support the infrastructure, for example, providing cognitive capabilities that help in monitoring and managing IoT devices, tackling the overload on the server to make the balance and conduct a traffic migration to handle the traffic on 


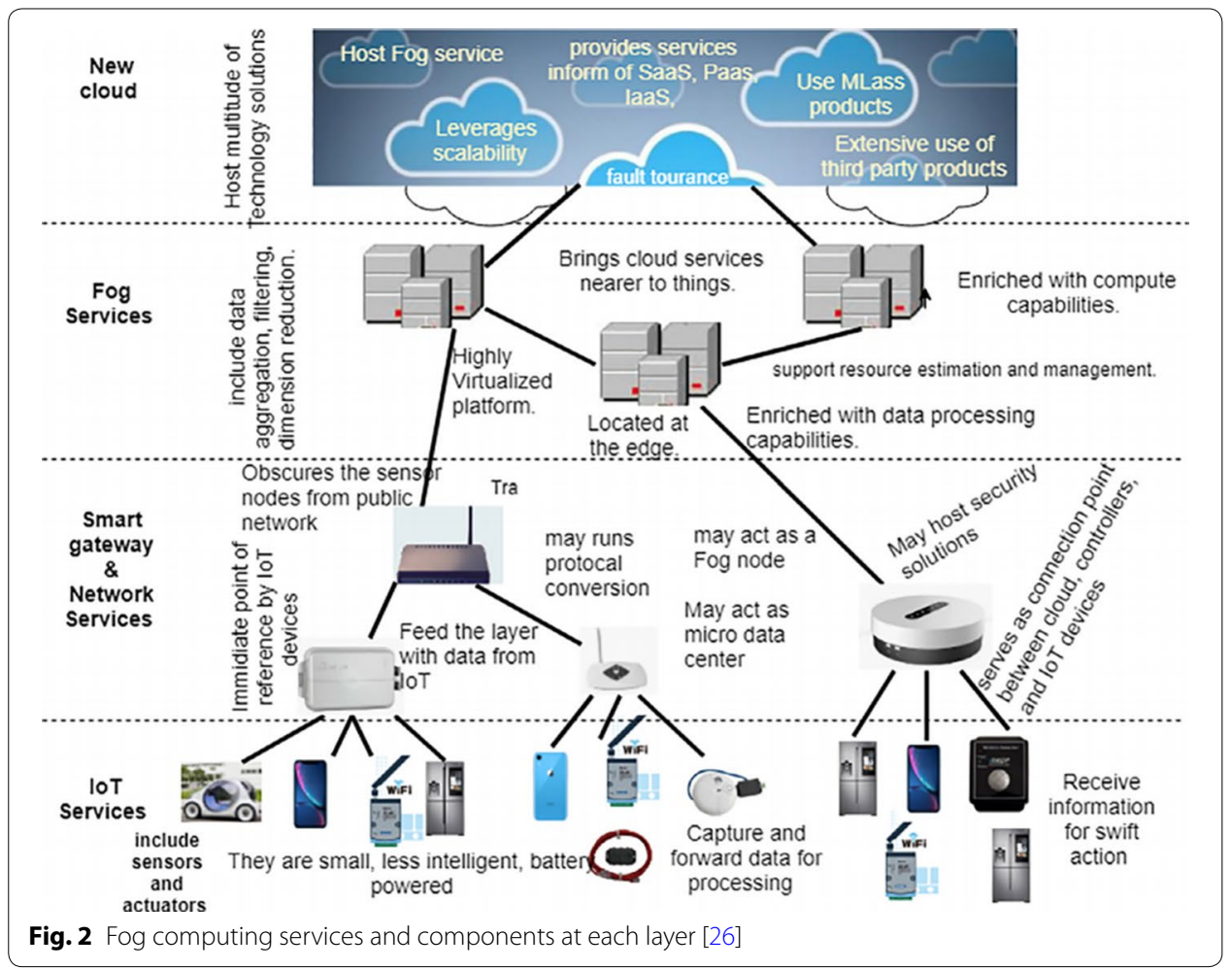

the server platform $[26,27]$. Reflecting this into education would greatly help in understanding the benefits of implementing fog computing into educational institutions. First of all, it helps to control all the IoT devices within the institution including sensors and actuators. Also, it acts as a gateway between IoT nodes and cloud which includes all the reliable software, platforms, and infrastructures and ensure the integration of fog services is well maintained.

\section{Fog computing in education loT systems}

According to Alli and Alam [26] Fog computing is a decentralized infrastructure computer which helps in computation, storage, and processing of data. Like the edge computing, this area of the cloud computing helps in bringing about certain advantages in the field of the information technology. One of the major benefits of using the fog computing in the system is the amount of time that it takes for fetching and processing information from the educational data bases. As per Bagheri and Movahed [28] the education industries go through numerous obstacles when it comes to the development of the educational norms. In order to cope with the modern concept of learning and provide the students with the understanding and the experiences, the fog computing technology has been very useful in some of the cases. According to Long and Siemens [29] the micro-data facilities are provided by fog computing which helps in providing on site technologies. These technologies are adaptable and can be used as per the requirement of the college. In the contemporary education systems, the learning management system or the LMS is one of the major ways in which the data and operations are handled. The major applications which are applied in these situations includes Procare, Skywar, and 
PowerSchool [30]. The facilities present in them must deal with the traffic as well as scale alongside making sure that the specific efficiency of the system is not reduced [31, 32]. But there may be downsize-down when everything and everybody is logged off. In order to work with such efficiency there is constant requirement of networking and good connection supply. This must be their top priority but can be very challenging especially for a distributed institution like a school, which can also be expanded across multiple branches. It must also be considered that some universities or schools might not have professional IT workers on sight for handling any situation. With the help of fog computing, the trained IT personnel can perform their tasks and manage the system remotely [33]. Content retrieval availability in educational systems have encountered a number of issues related. CDN servers have examined for instance, a bit rate selection strategy for video streams that takes into concern not only client and network parameters but also server abilities [30]. As a result, download time issue was pointed as one of major issue faced in the fog educational infrastructures. Furthermore, privacy issues such as consent management need extra work because users have access to behavioural information regarding students. It is also challenging to acquire and batch process data with various dimension from diverse sources, which may need different levels of intelligence [34].

Alghamdi et al. have proposed a process for content delivery by employing fog nodes. The flowchart process in Fig. 3 handles a number of challenges identified by Zolfaghari [30]. The process in Fig. 3 explains how to allow fog nodes to only cache the most popular content by implementing popularity-based caching strategy in order to handle some of the challenges, such as processing times, bandwidth rate, and overload on the memory [34]. Reflecting this into smart education will improve caching efficiency and will increase caching performance by making space for popular content.

There is a number of factors to criticize big data analytics utilization issues in higher education, where fog computing is implemented [33]. The first issue is based on the absence of data as a result of countless events, particularly in educational classes and communications with instructors and students. The process of gathering students' data from computer-based education is easy to maintain, but it is not so, providing that words of mouth communication is commenced. The term "words of mouth" is the word which is said by one person to another or to a group directly in a personal talk devoid of any media supply. The meaning of the words of mouth in the education practice is vital. However, confirmed data collection of this type is almost unmanageable [35].

The second issue of big data analytics in education focuses on the privacy of student's data [35]. Much information about student's behaviour is confidential like personal data that cannot be gathered without special approvals. Furthermore, tracing student's performance is required to be stretched by their personal information, for example, personality type. Though, several students are not willing to provide this type of information about them to the university.

The third issue of big data analytics in education is the veracity, which accepts including the extensively divergent qualities of data sources with major variances in the handling, correctness, and suitability of data [35]. This type of data occasionally cannot be investigated with the assistance of any tool. Though, the key points of Big Data practice in current higher education systems is focused on two major issues: lack of individual education and discussions between lecturers and students without information 


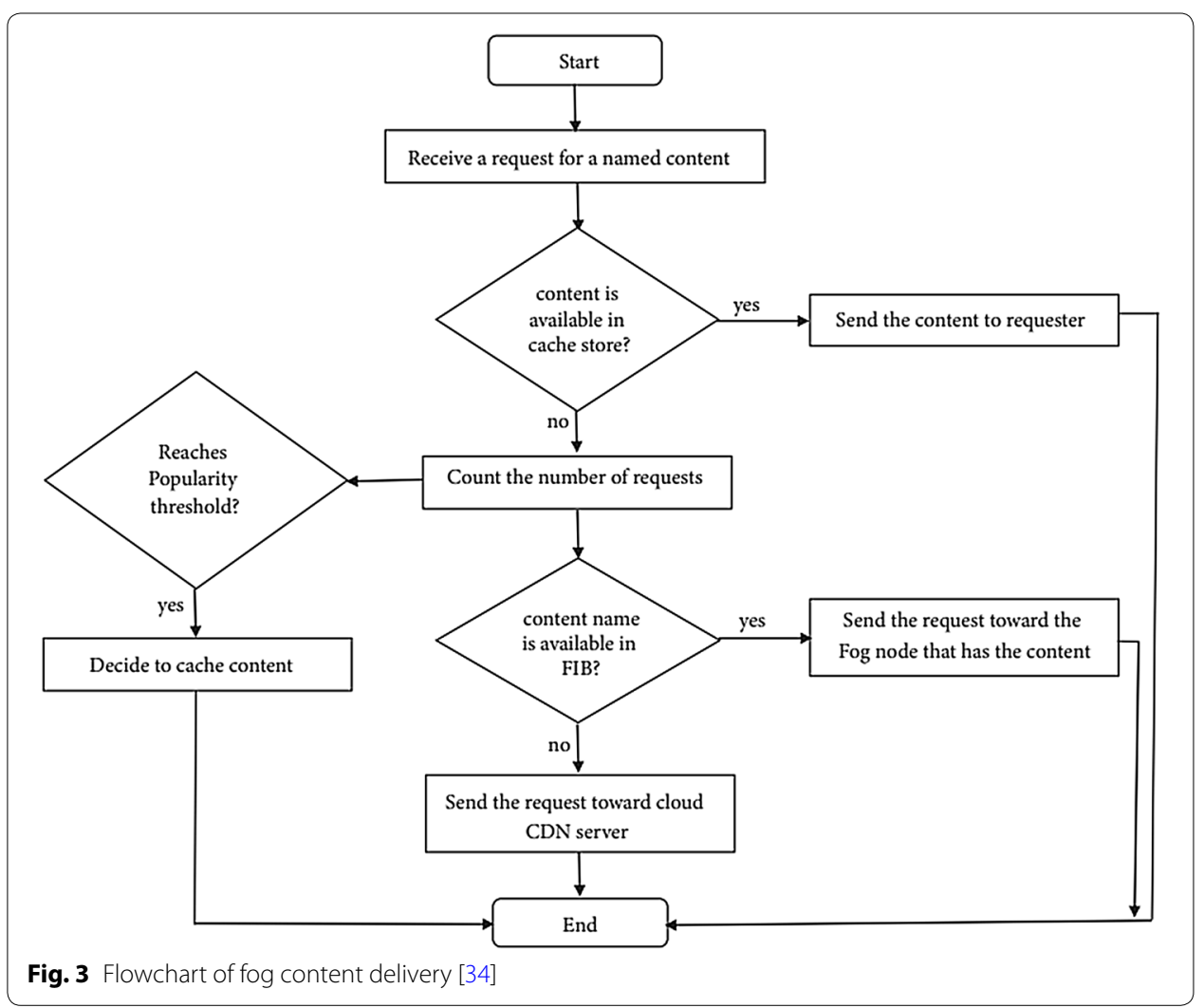

technologies usage and lack of different assignment types [33]. The first issue can raise depression of social isolation among students, while the second one is the result of current low level of educational quality [36]. Colleges that do not give appropriate arrangements of instructive materials and task type cannot grow full arrangement of vital aptitudes among their students.

The data engineering on the fog layer deal with data collection of different units from several sensors to perform calculations of different types of measurements. It is normal that sensor devices encounter some sorts of temporary disconnections that can lead to lose some data over periods [37]. Accordingly, the low-quality data of the reports received produce incorrect data that affect findings of any time cycle. For this reason, it is vital that all data acquired from all sensors must be constantly handled and curated spontaneously. Figure 4 represents the internal services involved of the fog layer.

The high-level architecture presented in Fig. 4 is designed to ensure that all messages received from IoT end-devices are supplied within the edge device properly in the creation of stream processing pipeline. After creating stream processing pipeline, initial processing of all data received from sensors based on generic data functions. At this stage, the key step is to identify inaccurate data that affect the study based on historic values and observations. The next is to address the transient disconnections that are leading to data loss. To address this type of disconnection, a simple algorithm can work well for identifying where the data is absent based on historic events. When this process is done, a continues data analysis to be conducted.

Fog as a service (FaaS) is delivering an inspiring opportunity for educational service providers. Fog service providers in the FaaS platform create arrays of fog nodes with an 


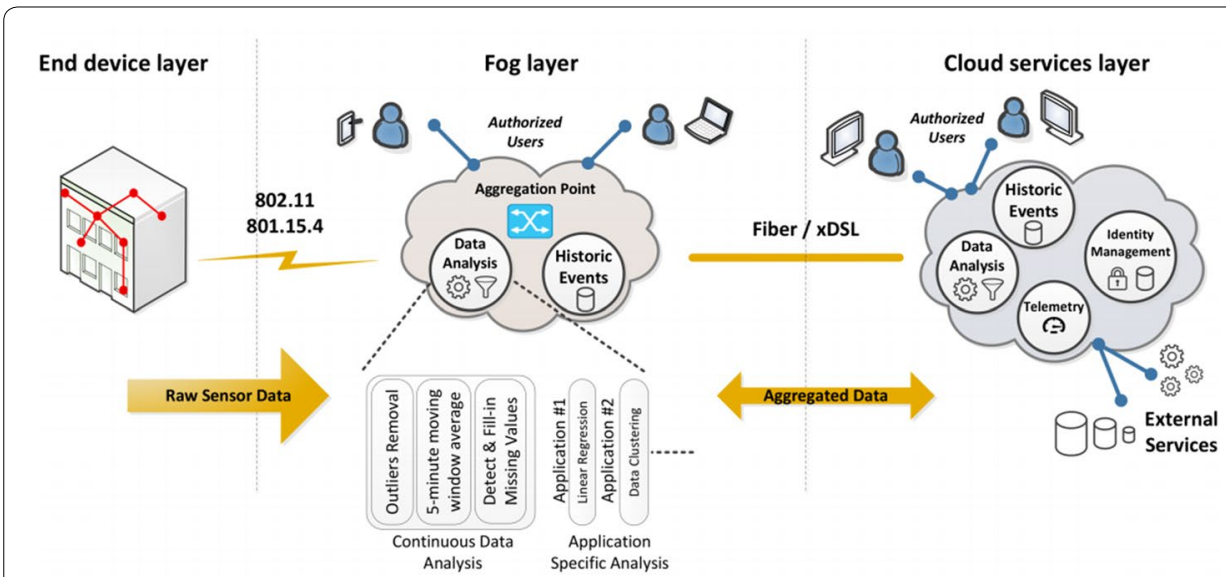

Fig. 4 Fog computing high-level architecture and data analytics for monitoring public educational buildings $[10,11]$

Table 1 Comparison of fog and cloud features [39]

\begin{tabular}{lll}
\hline Features & Fog & Cloud \\
\hline Latency & Low (locality) & High (eventual consistency) \\
Explicit mobility & Yes & N/A \\
Architecture & Decentralisation & Centralisation \\
Service access & At the edge/on handhold device & Through core \\
Local awareness & Yes & N/A \\
Geographic distribution & Yes & N/A \\
Scalability & High & Average \\
Availability & High & High \\
Number of users/devices & Tens of billions & Tens/hundreds of millions \\
Content generation & Anywhere & Central location \\
Content consumption & Anywhere & End devices \\
Software virtualisation & User devices/network equipment & Central corporate facilities
\end{tabular}

option of offering them at geographic locations to provide particular services to several end-users [38]. This could be beneficial for educational institutions that run a number of campuses in different locations. Accordingly, the technology of fog computing is considered as reliable architecture where data can be processed, analysed, and stored within the network through fog nodes instead of centralising data in the cloud. Table $1 \mathrm{com}-$ pares fog computing and cloud computing to identify the areas of differences.

The research also specifies that, the fog computing technology allows the IT Personnel to perform a lot of work, if not all, remotely, which provides numerous advantages like reduction of time delays and cost which may be involved in travel. This was supported by Bonomi et al. [40] that even the modern-day teachers want to make full use of the online resources or computer system in order to provide better education to their students. These modern technologies have grown so high in demands that its world-wide market in the sector of the education is expected to hike from $\$ 193$ billion in 2016 to $\$ 586$ billion in 2021, as supported by Research AND Markets. The utilization of Fog Computing, as mentioned by Raman [1] in universities having multiple campuses is quite prevalent 
because of its viability, simplicity, support, and the overall impact among the users. It is basically like a local computing but operated from a remote facility which can have the necessary efficiency, integrity, and information facility.

The main objective of this section is to ensure that the fog computing has been discussed properly for providing a better way of demonstrating the importance in education IoT systems. The IoT systems are used for the purpose of offering a better connected and collaborative future towards the education sector [28]. IoT devices have the potential to provide the students with better access and will also ensure that all the materials are communicated successfully among the student so that it becomes easy to provide real time experience towards them. Governance is considered as the most important method for the IoT education system. This ensures that each activity is determined effectively within the system so that the performance can be enhanced properly [41]. Fog based governance system is going to be developed for the purpose of providing easy access and management of the data flow within the education system. This will ensure that the governance process is executed with low cost. In addition to this for developing a successful governance system can be developed with the use of smart gateways and efficient IoT sensors [42]. The sensors will be responsible for determining the courses that are offered towards the students and the key activities that are performed within the education system. While storing and managing the data within an education system it becomes essential to ensure that the data are managed effectively with proper security and privacy [43]. With the use of fog-based application it becomes easy to manage the data that are accessed between the systems. Application of IoT are acting as a centralized point of administration for several sectors, such as education, medical, industry, financial, and other critical sectors as shown in Fig. 5. The fog-oriented system was proposed between the cloud and the end devices. This provides an intermediate layer and the main facilitator of al services delivered.

In teaching, the value of analytics and Big Data can be found in (1) their role in controlling change activities in higher education; and (2) how they can help instructors in improving teaching and learning. Learning analytics is basic for penetrating the fog that has settled over a lot of higher education [29]. Teachers, students, and executives need an establishment on which to institute change. For instructors, the accessibility of ongoing knowledge into the presentation of students-including understudies who are in danger-can be noteworthy assistance in the arranging of educating exercises [45].

Every system needs to ensure that proper privacy and security are introduced within the network for managing the access. The cloud access security broker protocol is used for the purpose of organizing the security between different layers of network [46]. This offers a wide range of security policies for the purpose of improving the features. CASB approach is used with the help of a modular approach. This model supports aggregating data from wide range of frameworks. Fog computing system architecture was designed for the purpose of managing the raw data associated with the activities that takes place within the education sector [47, 48]. The data identified as crucial are further forwarded to cloud for better management. With the use of smart education system, it becomes easy to distribute the data. With the help of advanced system, it will become easy to monitor the activities that are carried out within the education system [49]. The system will be able to provide better ability 


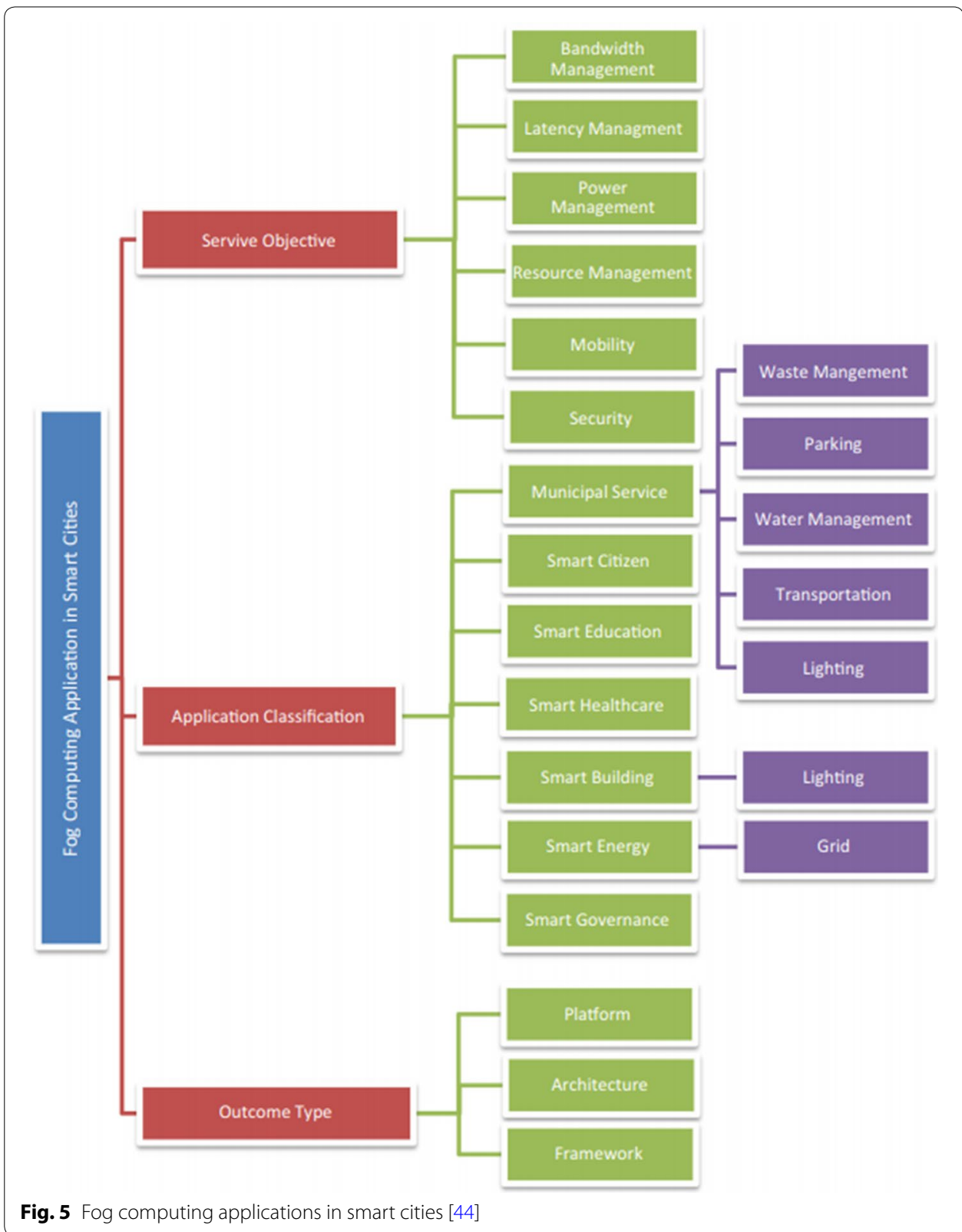

to governance the activities that are carried out within the system. The fog system has the potential to remove the issues such as security and reliability factors [50]. The education can be offered towards wide range of students. The three layers that are associated with the education system include fog layer, cloud layer and the IoT sensors.

Fog computing paradigm enables the micro data facilities for the purpose of providing modern on-site technology that can help in providing better facility towards the college need [14]. In order to have a better efficiency over the system it is important to increase the number of both staffs and the students that are accessing the learning management system. The most efficient applications that can be used for such 
computing purposes include the power school that is an oracle 12 the databases, skyward and a pro care. It is important to ensure that the operations are carried out efficiently after evaluating all the necessary networking requirements so that it does not impact the performance. The main advantage that can be obtained with the use of fog computing is that it offers it rained IT personnel and also helps in remote management of jobs [51]. Secondly with the use of modern technology in class it becomes easy to attract the students and also becomes easy to manage the online courses.

Interactive learning will become easy with the use of fog in IoT system. The textbooks will be linked with the web-based sites so that it becomes easy to offer better learning materials towards the students [52]. The study material includes animated videos, assessment, videos, and other materials for enhancing the learning process [53]. The main aim of using fog computing in the fields of education is that it will be able to provide better protection towards the learning courses and other facilities that are offered towards the students [54]. This will reduce the need of unwanted explanation and teacher's involvement. Fog computes is being implemented with the aim of providing better way of communication with the end users. This will offer interoperability, pre-processing, and heterogeneity within the cloud. It has been observed that the fog computing has the potential to offer better proximity towards the end users [55]. In addition to this the use of fog computing also offers decentralized computing so that better support can be offered efficiently towards the education system. The quality of services can be enhanced with the use of fog computing. Thus, it can be stated that with the use of proper technologies it becomes easy to manage the services. After analyzing the wide range of benefits that are offered with the use of fog computing it can be stated that the scalability, mobility, awareness, and reliability increases within the architectural layer [56].

\section{Related works}

\section{IoT in enhancement of education}

IoT or Internet of Things is one of the most revolutionary technologies developed in the twenty first century which has seen rapid growth and spread in various sectors of livelihood. With more and more applications of IoT getting developed day by day, its usage in the industrial, healthcare, and manufacturing and more recently in the field of education as well. Several experts are trying to create educational platforms in the schools and other educational sectors by applying IoT [57]. It can enhance the learning experience of the students as well as the teaching experience of the teachers. With the popularity of the other IoT devices in various sectors, its possibility of innovation and many others, this is definitely a promising aspect in future. A few of the advantages which IoT can provide to a school are as follows.

Security is one of the best areas for the application of IoT [58]. It must be considered that the IoT can make a school or any other educational institution much safer with the help of security features like alert signals, alarm calls, safety announcements, precautions, alert or panic buttons, door locks, sensors, security codes and many more. IoT can provide alert against any possible intruders in a school or college with the use of laser sensors, alarms and others and even the teachers may have access to alert buttons which can help them take actions in those situations [59]. Thus, IoT has the power of making all the people in a school safe, be they students, teacher, or any other staff member, 
which is a big relief in any situation. Not only physical security, but data security is also a major aspect where IoT can help. An educational institution handles a lot of data and other sensitive materials which may include personal details of students, teachers or staffs, bank details and other financial information, information regarding the education progress of students and even the examination question papers and answer scripts, all of which are vulnerable to data breaches [51]. Hence, securing them is a big bonus which any educational institution would accept with pleasure.

IoT can be a major bonus in the academic section of a student as well. Provision of a perfect platform is important for better education [60]. IoT controlled LED lights are better for students as compared to fluorescent lights. Not only lighting but provision of audio-visual learning is another major benefit of IoT. IoT can help both the teachers and the students with such applications as it not only clears the doubts of the students well making them understand better but also helps the teachers in teaching properly. IoT provides teachers with every tool at their disposal for the teaching purpose. It can suggest books for them clear any doubt which a teacher may not know, stating facts and quotes or even perform visual experiments for the class [28]. Not only that but it can help out the teachers in the correction of the examination papers and assignment as well. All these could make small differences in the day to day learning and teaching experience and as a result, a better learning platform is provided [61].

Betterment of learning experience is not the only advantage of IoT, but it has found its applications in the management department as well [23]. Management can be totally revolutionized with the application of IoT [62]. A lot of paperwork can be handled efficiently and smoothly with the use of IoT along with scheduling maintenance and monitoring of data and resources. The entire management staff associated with the educational institution can reap its benefits. Starting from financial matters, admission of new students, teachers, and staffs to other important tasks like helping during meetings and other works. Even the invigilation during examinations is possible by its use [63].

Automation of an entire school may sound expensive, but in reality, it is often cheap and efficient in the long run. Lights, fans, or air conditioners present in a school can be automatically shut off if they are not needed. Remote controlling allows them to be operated without any problem over a large distance. The faults and problems in the school systems can also be detected easily. Efficient functioning allows for the reduction of energy consumption and thus the cost can be reduced like that. The requirement of human resource can also be reduced and that reduces the cost as well.

\section{Current methods}

Specific framework discussed here is applicable to enable technologies for fog computing in education IoT system [52]. The framework is considered as the leading parameter for those were target of searches use shared fog nodes, smart gateways in terms of fog nodes. Before enabling useful technologies for fog computing specifically in education IoT system, the detailed architecture of fog computing should be implemented according to requirement as designed in Fig. 1.

At first, the nodes that are shared within fog computing must be planned at the early stage of development. In order to distribute the decision-making tasks through shared fog nodes and smart gateways the new edge mesh computer paradigm is used. 
It is recognized that, the personal gateways positioned in the student side server like intermediate nodes $[10,11]$. For processing student-oriented data, the intermediate node is generally used. Secondly security of the server must be maintained accurately by the development team associates.

In order to facilitate the resource sharing between all the related fog nodes an effective algorithm has to be applied. How the fog nodes will be connected to individual education IoT system related applications, for gateways need to set accurately [64]. Two different algorithms are proposed. The first one is to pick the best applicable fog, whenever users are at the overlapping part. The second algorithm proposed will help to resolve situational difficulties [65].

In order to enable technologies for fog computing in the education IoT system the most important part on which the developers need to keep focus is the fog architecture. The proposed one is a six layered architecture comprises of physical or virtual layer, monitoring layer, pre-processing layer, temporary data storage layer, security layer and transport layer $[66,67]$. In order to earn good academic records implementation of fog computing in education IoT system is very essential. The physical or virtual layer is comprising of virtual sensor network, wireless sensor networks, physical sensors, and virtual sensors. The monitoring layer will conduct all activities that help monitoring needful operations [68].

The monitoring layer operation individually monitors power supplies, resources, response of the students and lecturer over education and other services [69]. The pre-processing layer suggested in this fog architecture is applicable for data analysis, filtering data, trimming and reconstruction. The temporary storage layer of the architecture will distribute and replicate data. For storage space virtualization the temporary storage layer will be configured [64]. Maintaining overall security is also essential to keep confidential data related to students and employees secured from external users.

Fog computing architectural layers are defined as a decentralized technical infrastructure used to compute, store, and apply data located in the cloud. The advantages of fog computing are nowhere different from edge computing. For improving education efficiency fog computing is recognized as to be very essential [55]. In order to improve overall security of education IoT system, fog computing is most effective than any other. Fog computing and Internet of Things are two widely connected technologies. The applications where cloud computing is found as not enough viable, fog computing is used. This specific distributed approach helps to address the industrial IoT and IoT requirements [70]. The issues of extra time consumptions and smart sensor operators get resolved with implementation of fog computing in the education IoT system.

It reduces the required bandwidth and also reduces the back and forth communication present between cloud and sensors that may negatively impact the performance of the Education IoT system [71]. The net amounts of information sent in the cloud get reduced in fog computing [72]. It helps to converse the network bandwidth to get better the entire response timing [73]. The data confidentiality is maintained than the general cloud computing technology. It supports the mobility and minimizes internet latency and networks. However, in some cases the application may face authorization 
and data authentication issues. Apart from that privacy issues can also occur [74]. Security issues such as spoofing, man in the middle issue also may occur in case of fog computing.

Smart electronic education gateways are integrated in this system to connect individual devices. In order to pre-process alternatives and other data the suggested E-Education system is very essential. The personal gateways used here will act as intermediate nodes [47]. In order to give rich and understanding experiences, these days' education industry IoT system is facing major obstacles. Students and teachers both are needed to have options to access modern day technologies. Digital focused learning will improve the teaching and learning process as a whole. In other words, for both trainers and trainees fog computing is essential [75].

\section{System development}

The efficiency of data storing and data accessing becomes easier and quicker with enabling fog computing in the education IoT system. These days most of the higher institutions are implementing regular office applications, online desktop, messaging services to hold web level solutions for students and teachers much specifically. According to Parikh et al. [12] the issues of traditional cloud computing and IoT Technologies also get resolved with application of Fog Computing because of its lower latency. The response time in fog computing is lesser than any other immediate technologies.

The fog computing technology is comprising of three main work packages in terms of method selection, system development and review through survey. The method is comprising of detail framework and model. On the other hand, Zhang et al. [76, 77] stated that the system development activity is comprises of architecture and system that is implemented. Final framework holds shared fog nodes and smart gateways. A data centered fog platform needs to be developed at the initial stage of implementation [78]. In order to provide onsite technology that can scale up and down according to college requirements fog computing enables important micro data facilities. Even if it is found that the university lags IT experts can also use fog computing technology in their education IoT [73]. In order to build sub network, individual smart objects are linked up to fog edge nodes. For building time to time communication fog computing has to be implemented in education IoT system.

For processing huge dataset firework model is designed, planned, and developed by developers in cooperative edge environment [79]. In order to improve the education IoT system in universities proper data integrity and security among employees, teachers and students has to be maintained accurately [80]. Cloud IoT platform performs horizontal roaming and vertical offloading migration that are again organized in three layers' protocol. The proposed security scheme is an end to end architecture. For transmitting both tactical and non-tactical information this model is much effective and essential as well [81].

Intelligent computations to the smaller and autonomous units are successfully distributed followed by this model and framework-based application [66, 67]. The inabilities associate to the current education IoT system got resolved with the implementation of fog computing in the application [62]. In order to collect huge set of real time data this particular predictive model is developed considering cyber manufacturing. The newly 
enabled fog computing system would be able to support IoT education system. IoT system helps universities to make the education approach much accessible in geography, status as well as abilities [82].

According to Liu et al. [82] IoT technology can be integrated successfully in the university environment. For building a broader application in education system IoT gives solid foundation. Immersion is defined as one of the most powerful mechanisms used to select and learn best suited foreign language. The secret weapon for this application is real time feedback generation [83]. Infact teachers would also be able to provide real time feedback to the students whenever required. In order to check whether students have made all accurate statement selection and usage IoT system stands beneficial [84].

Student's progress monitoring and performance analysis become easier and quicker than previous traditional approach. It helps to connect classroom to form up a digital presentation [85]. Special education, physical education, school operation security, classroom monitoring and personalized learning become enabled with this system approach [43]. However, in this paper not only the benefits but also respective disadvantages associated to this technology are also elaborated in this paper. The performance of fog computing in education IoT system is also evaluated in this paper in a sequential process.

\section{Review and survey}

In order to describe fog computing features in education IoT in Fig. 6, firstly different and similar articles will be reviewed and survey accordingly. For protecting data related to students, teachers, and employees as well fog nodes are important as it can connect other fog nodes [86]. In order to gather used information from various resources similar papers and detail survey is conducted. Hussain, [87] stated that, fog computing is a geographically distributed architecture that can connect multiple numbers of heterogeneous devices ubiquitously with the network structure of

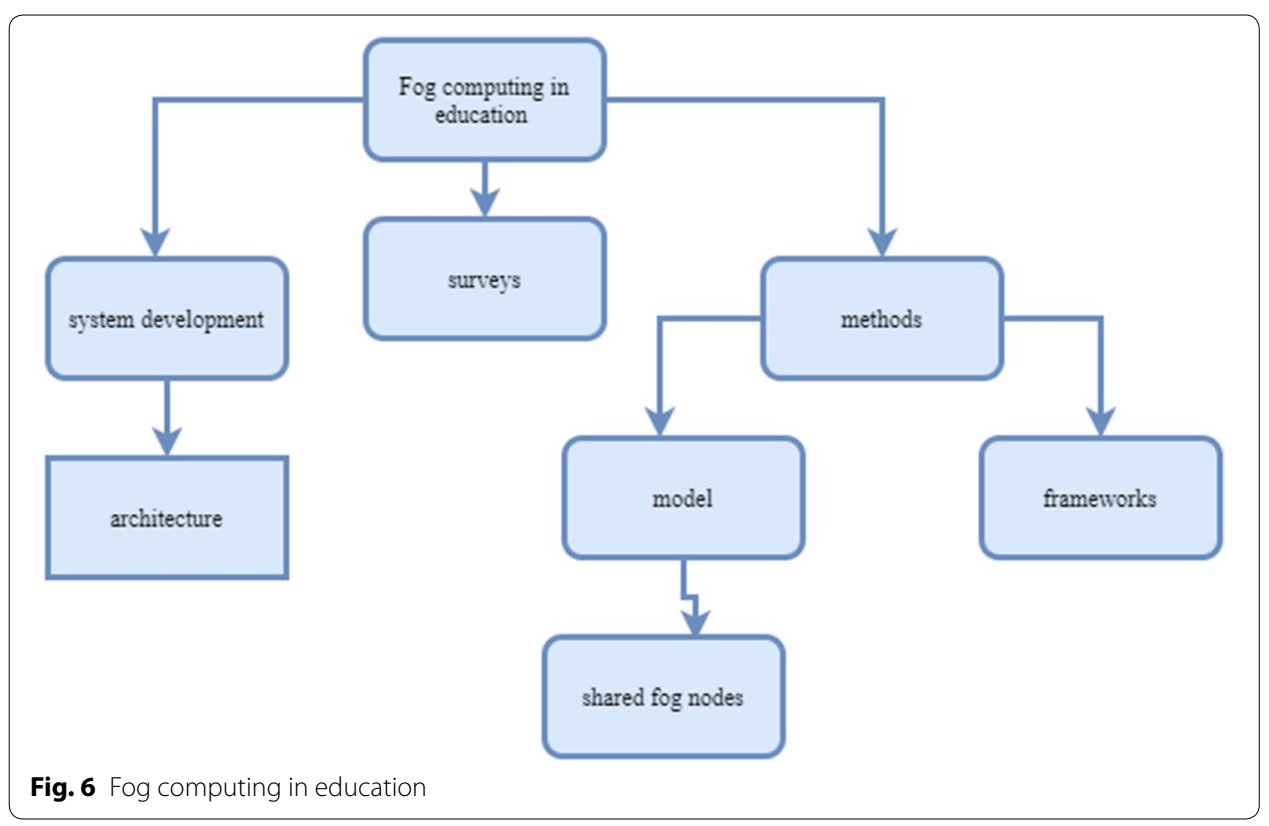


university. Whether enabling fog computing in the education IoT system is beneficial or not is reviewed through survey and secondary analysis.

According to Borthakur et al. [68], fog computing processes easy computation, flexible communication between teachers and students. It also gives faster data storage and data access abilities to the university associates. It gives real time response with lower latency [86]. The education process distribution becomes secured, scalable, and distributed in nature after enabling fog computing technology. In contrast to cloud computing fog computing stands better [65]. Data security, storage and access capabilities of education get improved with fog computing technology. The Fog computing technology always works better in IoT architectures [88]. It is reviewed that fog nodes play important role in fog computing.

Fog nodes help to receive real time data. It also enables real time analytics applications. System can give response within milliseconds after introducing fog computing technology in the IoT applications [89]. However, it provides temporary information storage unless all useful data get transferred to cloud storage [85]. Fog computing send periodic data summary those are collected from various cloud devices. For the IoT based education system enabling fog computing technology is always more beneficial than cloud computing technology [90]. Fog computing can include cloudlets at the network edge and due to this it helps to create better and much powerful data center. All the resource intensive IoT systems are supported by the fog computing technology [91]. The operational differences occur between cloud computing and fog computing because fog computing is decentralized but cloud computing is not. Fog computing technology works as an intermediate application between hardware and software associated with remote servers [87].

Information that need to be transmitted to the university server are regulated by fog computing [92]. Some of the issues of cloud computing gets resolved with fog technology. All the related users would be able to access the server much easily. It also gives immediate response than any other technology [93]. The chances of error occurrence minimize because in fog computing information are segregated into small pieces and never send all together.

Issues of connection loss are resolved because it holds multiple numbers of interconnected channels. It is reviewed that fog computing gives higher security as in this cases data are processed through multiple numbers of fog nodes in complex distributive system [52]. Experiences of the users get improved a lot due to real time and immediate response. Any query raised by students will reach the teachers immediately and similarly teachers will also be able to give immediate response on the queries [94].

On the other hand, Okafor et al. [19] argued that there are some disadvantages also associated to fog computing technology. Fog computing is a complicated system because it holds additional layer of data processing and data storage. Due to technical and operational excellence it holds additional expense than cloud computing technology [95]. In order to operate the application easily the universities should buy edge devices in terms of routers, gateways, hubs etc. Fog computing has limited scalability,therefore, it is not scalable like cloud computing technology. Fog computing 
can fulfil the demand of increasing numbers of devices [96]. The bandwidth related and remote computer resource related issues get resolved with fog computing.

Fog computing tends to offer better decision-making process and also ensures that all the relevant data are managed within the cloud. Fog computing ensures that the data are analyzed within the time so that it becomes easy to manage the data within the cloud [97]. The fog computing performs their functions in milliseconds and ensures that all necessary data are evaluated within the system successfully. The article has focused on evaluating the way fog computing works has been discussed within the paper. Gateways are designed with the aim of providing a better way of storing and organizing the data [91]. The key components those are associated with the development of fog architecture includes device, fog computing and cloud for handling the complex data [98]. This ensures that the speed, latency, and variety are being designed properly for managing the performance. The paper has also focused on evaluating the roles that are played by the fog nodes. Table 2 demonstrates the problems of existing models and frameworks of fog computing applications in higher education along with techniques followed in order to solve the issues identified.

Education industry has the chances of encountering a wide number of obstacles that gives rich understanding towards the students. Fog computing has the potential to enable the micro data facilities for the purpose of providing modern on-site technologies [83]. This will also ensure that the latencies have increased for the purpose of improving the individual experience.

It has been observed that fog nodes are extremely vibrant. Fog computing ensures that the users are capable of managing the data with the use of different gadgets [104]. Both the computing technologies that are fog computing and edge computing has the potential to provide the functionalities in the terms of using analytic systems that are located on the different sites of the system. Hence it can be stated that with the help

Table 2 Frameworks and models for the fog computing in higher education applications

\begin{tabular}{|c|c|}
\hline Problem & Technique \\
\hline $\begin{array}{l}\text { The pre-existing technology does not use edge com- } \\
\text { puting mechanism [99] }\end{array}$ & $\begin{array}{l}\text { Use of new computing paradigm for improving the } \\
\text { performance. The edge mesh is considered as the } \\
\text { smartest computer paradigm for managing the } \\
\text { centralized server }\end{array}$ \\
\hline $\begin{array}{l}\text { Response rate is slower in case of managing sensitive } \\
\text { data [100] }\end{array}$ & $\begin{array}{l}\text { Implementing two algorithms: (1) integrating fog for } \\
\text { determining the user's data, (2) identifying the short- } \\
\text { est path for using fog computing }\end{array}$ \\
\hline Prevention of DDOS attack & $\begin{array}{l}\text { Integrating handshaking method for ensuring the } \\
\text { authentication process effectively within the system } \\
\text { [101] }\end{array}$ \\
\hline $\begin{array}{l}\text { Challenges faced by developers while accessing loT } \\
\text { systems }\end{array}$ & $\begin{array}{l}\text { Using API gateway for the purpose of connecting the } \\
\text { micro services }\end{array}$ \\
\hline Current system fails to provide proper governance & $\begin{array}{l}\text { Introduction of computation framework for managing } \\
\text { the remote real time monitoring }\end{array}$ \\
\hline $\begin{array}{l}\text { Communication process gets hampered and eventu- } \\
\text { ally leads to impacting the student's data [102] }\end{array}$ & Using eWall monitoring system \\
\hline $\begin{array}{l}\text { Improper monitoring and governance of the activities } \\
\text { carried out within the higher education [103] }\end{array}$ & $\begin{array}{l}\text { Use of smart gateways in the fog computing process for } \\
\text { enhancing the way performance is monitored }\end{array}$ \\
\hline Problems faced while decision making phase [24] & $\begin{array}{l}\text { Implementing cloud to fog architecture for securing the } \\
\text { edge of the network }\end{array}$ \\
\hline
\end{tabular}


of proper technologies it becomes effective to interact with the students using fog computing [93].

Fog paradigm is one of the most appealing and promising approach that help with several services towards the users. However, there are certain sections of issues that are identified while performing the survey. It has been observed that there are certain security issues and that comes along with the cloud computing factors. The security and privacy concerns have the ability to impact the whole system [105]. Therefore, it is equally important to survey the issues that are associated with the utilization of fog computing in education system. According to the open fog consortium it has been observed that there are five different ways through which computing can enhances their end point security. It has been observed that fog computing acts as an added layer of protection between IOT devices and the web server for providing better security [106]. Fog computing has real time incidents report for the purpose of linking IoT systems together. This new computing feature will be capable of bringing better enhancement in the education.

\section{Findings of the related work}

After undertaking a detailed research on the chosen topic of discussion, I have identified some of the major aspects of two of the most discussed technology, that is internet of things and the fog computing. From the initial discussion I can gather the idea of the infrastructure and the framework of the internet of technology and the ways in which fog computing technology can help in enhancing the operations of internet of things to make it fit and suitable for usage in educational institutions.

Educational institutions are not only surrounded by the student, there are other aspect of the system as well. From the researchers who have conducted researches on the technology have identified some of the major benefits of the technology, like the ability of the technology to improve the operations of the system, the ability of the system to sense the presence or absence of the people to act automatically by shutting the lights and fans off and numerous others can provide, additional support to the education system. With the usage of the fog-based system, data backup can be generated. The security of the data can be monitored with the help of the technology from a remote location. All these are some of the significant benefits of using fog computing and internet of things.

From one of the articles discussed in the related work section, I can identify one of the major issues of using the technology that is the delay of time. Due to the usage of these application, some of the systems present in the institutes take time to respond. These are the results of the unavailability of the network or connections. Not only is that, that the technology is not quite useful without the usage of the internet services and it is quite evident from the research.

Fog computing is considered as the most effective way of sharing and managing the data. This also offers wide range of benefits. However apart from the emerging benefits there are certain disadvantages that have the potential to hamper the performance. The wide range of limitations has the potential to impact the performance of the facilities offered at the higher education. Fog computing strategy has inherited some issues from the cloud computing in terms of security aspect. Privacy and security aspects are considered as one of the main concerns while using the fog computing method. The accuracy 
and adaptability get hampered due to full outsourcing of data. Beside the wide range of benefits that are offered with the combination fog and cloud computing there are certain issues that hampers the performance. This issue tends to arise due to architectural limitations. Secondly, the broadcasting of every data shared within the different layers of fog computing leads to data redundancy and congestion among the data. This creates a major issue while managing the storage and data effectively within the system. Apart from this the fog computing technology also lacks offering features such as cooperation and load distribution. These features are not described in the fog computing architecture and thus it becomes difficult to manage the data within the different layers. The main reason behind using edge computing is that it has the potential to increase the network performance by minimizing the latency rate. However, it becomes very difficult to handle multiple applications together at a time. This hampers the way data are processes within the system and also leads to increase in latency. After analyzing the architectural structure, it can be stated that there are possibilities of several issues that can hamper the services that are offered with the use of the fog computing.

Apart from this the major issues that are faced with the use of fog computing is with security issues in the wireless devices and the related privacy concerns. Secondly the authentication is considered as the most concerned aspect in the fields of fog computing. Due to huge number of involvements among the cloud providers and service providers it becomes difficult to manage the trust and also the flexibility gets complicated. This hampers the overall performance and also can lead to launching attacks for hampering the overall performance of the system. The security concern arises with the use of fog computing due to number of devices that are connected within the fog nodes. In this type of hacking the IP addresses can be faked by the hackers for the purpose of obtaining the information that are shared within the system. Thus, it can be stated that fog computing has the potential to handle massive data that arises with the use of IoT on edge of the network. However, the drawbacks of using fog computing has the potential to hamper the overall performance. Thus, there is a need to integrate proper structure for enhancing the performance.

On the other hand, there some solutions can be implemented in order to tackle the identified issues and challenges presented in the survey. Identity authentication to maintain identity management would be one of robust solutions which can be implemented to prevent users' privacy leakage in the fog platforms where IoT applications are installed. By using this mechanism, the user will be checked to guarantee the credibility and authenticity before getting access to the services. Applying role-based access control policy is one of effective techniques to confirm to which level user can access to. In order to deliver reliable services and protect users' data, a number of security protocols can be combined together for making the hacking process more complex and to stay safe. The protocols which can be implanted in the fog are asymmetric data encryption, spam detection, authenticated key agreement, and digital signatures. Intrusion detection system is an integral part of security and most valuable component in the network. In fog computing, hacking can occur without having proper security detection tools. This tool is set up to detect any suspicious activity within the network and provide different types of alarms, depends on the criticality of the risk identified. It is responsible for detecting any activities conducted in IoT devices and fog nodes. It also can detect any policy 
violations. Fog computing is vulnerable to Sybil attack. This type of attack is allowing hackers to fake identities which can help them gaining unauthorised access to sensitive information and compromising IoT applications and real-time services. Therefore, a mobile sybil defence scheme has been proposed by Quercia and Hailes in 2010 to match the communities of mobile users and identify the trusted users in untrusted communities as sybil attackers [107]. This feature is to distinguish between the normal user and attackers.

Other credible solutions could be considered to tackle some of security and privacy challenges of secure data sharing transient storage that allow users to temporary process data in the fog nodes generated by IoT devices. Implementing proxy re-encryption, key aggregate encryption, and attribute-based encryption will act as a protector when it comes to secure data sharing and data integrity. Also, big data analysis needs to be fully secured. This can be achieved by applying fully homomorphic encryption, and differential privacy.

\section{Discussion and open issues}

The key objective of the paper was to identify the research that have been carried for the purpose of understanding the role of fog computing in the field of education IoT systems. In the process of developing the taxonomy, the related articles with fog computing are analysed. The review focuses mainly on reviewing the concepts that are associated with the fog computing in higher education fields. The paper has also evaluated the critical infrastructures that are used for sharing the resources. Fog computing thus plays a crucial role in managing the data and activities. This section is responsible for determining the features that are offered with the fog computing in the fields of education applications. The discussion and open issues section will include performance evaluation, motivations, challenges, and issues identified from the literature and future directions on fog computing.

\section{Performance evaluation}

Performance evaluation is the technique that is used for determining the various resource sharing techniques that took place in fog computing of education IoT systems. The paper has focused on evaluating the resources that are needed for managing the resources associated with the performance. This includes the factors of providing low latency, decision making process, real time processing and providing proper response time. This also ensures that the feature such as energy consumption, bandwidth maintenance and mobility also get enhanced. However, it has been observed that there are several issues that are faced while using the fog computing paradigm. Thus, there is a need to engage the way data are managed and protected within the network. Firework paradigm is one of the new computing paradigms that were proposed with the aim of facilitating better way of data sharing. This paradigm ensures that the data sharing facility is maintained with proper data privacy and integrity for the stakeholders. Moreover, the way data are handled can be modified with the use of proper security processing. The reason behind using an integrated and flexible computing paradigm is to benefit the critical application that takes place within the system. The critical applications that are 
performed by the higher education system is preparing the mark sheet, managing the admission process, and hiring students.

The wide range of benefits that are offered with the use of fog computing includes reducing the chances of data transmission latency, reducing the end to end delay, and ensuring that quick response time. From the above analysis it can be stated that fog computing has better features as compared to cloud computing in the field of education application. This ensures that the time is saved while accessing the data and also the execution time can be reduced. The paper has explained the importance of real-time governance that is designed for the purpose of reducing the transmission related issues. It is important for every member within the system to maintain proper communication procedure for ensuring better performance. The advanced services that are likely to offered with the use of fog computing in the higher education field is that it will secure the way data are transferred and will also ensure that every communication process is managed effectively. The focus of the assessment us to reduce the latency and improving the quality of service that is offered towards the student.

\section{Motivation}

Education sector has used several technologies for the purpose of improving the performance. There is a need to manage the resources effectively so that the performance can be enhanced. In order to enhance the way resources are managed within the education IoT system is by using the three process that are computation offloading, load balancing and the interoperability. The main reason behind using fog computing in the fields of education is to ensure that the major issues faced by the previous architecture are being mitigated successfully. For the purpose of providing better support towards the system it is important to use proper architecture of the fog computing. Thus, it can be stated that in order to have a better computing procedure it becomes essential to develop a real time system that will be capable of managing the performance.

\section{Challenges and issues}

Fog computing and edge computing has gained huge importance in education sector. However, it has been observed due to huge amount of challenges it becomes difficult to implement the computing process. The shared resources feature has the potential to impact the performance of fog computing. Apart from this the other technical knowledge needs to be mitigated properly for the purpose of improving the performance.

\section{Authentication}

One of the major issues in the cloud computing or the fog computing is the challenges of authentication. This is because, with the technological advancement, the hacker's activities have increased the threats to the data and information available on the cloud. If they are compromised the entire system will be at stake. The main security issue is the authentication that is offered towards the device that is associated in fog computing in different gateways. It has been observed that each appliance continues in their unique IP address. With the help of a fake IP addresses it becomes easy to access the information that is stored on a particular note. The security issue is hampering the system 
performance very rapidly. Therefore, it is essential to overcome these challenges with the help of an intrusion detection system.

\section{Privacy issues}

The fog computing operates with networks. Thus, it can be stated that network privacy becomes a very big concern. It has been observed that the network operator tends to generate a configuration manually. However, the fog nodes that can get impacted due to lack of proper protection can cause harm towards the sensitive information. The sensitive information that is stored over the network can be easily collected by the hackers for the purpose of hampering the performance. Therefore, with the help of encryption method it becomes easy to encounter these issues.

\section{Network management issues}

It is observed that the network management between the heterogeneous devices becomes very difficult as these faces issues with managing the fog nodes, the network, and the connection between each note. Therefore, in order to resolve this issue, it is important to develop SDN and NFV techniques.

\section{Issues regarding the delay}

Apart from all these it has been observed that there is certain delay that is observed at the data aggregation time. Data aggregation may take several times for processing the resources. There is a need to have a proper control so that the delay in completing process does not hamper the performance.

\section{Issues regarding the absence of expertise}

As the technology is still in its emerging phase, this is one of the major issues. The employees and the IT experts are barely expertized in the field of the technology. Not only that, the infrastructure in the education system is not that developed in majority of the institutions, thus training the teachers and other employees regarding the usage of the technology becomes very difficult.

\section{Recommendations}

The recommendations are provided for the purpose of managing the resources effectively. While developing fog architecture it is important to focus the latency and reliability of the system. The total time consumed by the system can be reduced by re-planning the development process. Moreover, there is a need to develop a real time response system that will be capable of providing better support towards the education system.

\section{Learned lessons}

Fog computing is one of the most emerging technology that offers wide range of benefits. However, it is important to understand all the factors properly so that it can be utilized in an effective manner. In order to analyse the different components related to the fog computing several research papers are identified so that it becomes easy to 
gain the knowledge. With the help of several articles and journals it became easy to identify the benefits and the issue that comes along with the utilization of cloud computing. It can be stated that with the use of fog computing in the fields of education system is that it helps in monitoring the education related activities and also ensures that each data is managed successfully within the system.

\section{Conclusion}

Thus, from the above survey it can be stated that with the use of Fog computing it becomes easy to manage the research and the way IoT can be used in education fields for the purpose of improving the performance. The IoT in enhancement of education along with current methods and system development subsections of related work have demonstrated how the aspect of the current system of education makes the introduction of the fog computing and IoT technologies an obvious factor along with stating the major benefits of internet of things. Fog computing was evaluated in the discussion and open issues section against the performance attributes in order to demonstrate How fog computing technologies can be utilized in educational IoT systems to provide high level of accuracy, privacy, security, and agility. Fog computing offers a better control over the privacy concept so that it becomes easy to manage the data within the system. With the use of fog computing it becomes easy to increase the business productivity and the agility also gets improved. Thus, it can be stated that with the help of fog computing it becomes easy to improve the productivity and also the speed of the business performance gets enhanced. The paper has focused on preparing an effective fog computing technology for the education IoT system so that it becomes easy to manage the services offered. In this paper the major benefits and features of fog computing implementation are determined. Along with this the key issues that related to the fog computing are also determined in the paper. In addition to this the paper has also provided a methodical review for the purpose of depicting the methods that are essential for analysing the features related to fog computing. Thus, it can be concluded that with the help of this survey paper it will become easy to carry out the future research.

\section{Acknowledgements}

Not applicable.

Authors' contributions

Not applicable.

Funding

The author received no specific funding for this work.

Availability of data and materials

Data available within the article.

Competing interests

The author declares no conflict of interest.

Received: 19 May 2020 Accepted: 1 November 2020

Published online: 12 November 2020

\footnotetext{
References

1. Raman A. Potentials of fog computing in higher education. Int J Emerg Technol Learn (iJET). 2019;14(18):194-202.

2. Ray PP. A survey on internet of things architectures. J King Saud Univ Comput Inf Sci. 2018;30(3):291-319.

3. Jeschke S, Brecher C, Meisen T, Özdemir D, Eschert T. Industrial internet of things and cyber manufacturing systems. In Industrial internet of things. Cham: Springer; 2017. p. 3-19.
} 
4. Al-Doghman F, Chaczko Z, Ajayan AR, Klempous R. A review on fog computing technology. In: 2016 IEEE international conference on systems, man, and cybernetics (SMC). IEEE. 2016. p. 001525-001530.

5. Peng M, Yan S, Zhang K, Wang C. Fog-computing-based radio access networks: issues and challenges. IEEE Network. 2016;30(4):46-53.

6. Hao Z, Novak E, Yi S, Li Q. Challenges and software architecture for fog computing. IEEE Internet Comput. 2017;21(2):44-53.

7. McRae L, Ellis K, Kent M. Internet of things (loT): education and technology. Relatsh. between Educ. Technol. students with Disabil. Leanne, Res. 2018. p. 1-37.

8. Ye D, Wu M, Tang S, Yu R. Scalable fog computing with service offloading in bus networks. In: IEEE 3rd international conference on cyber security and cloud computing (CSCloud). IEEE. 2016. p. 247-51.

9. Aazam M, Huh EN. Fog computing micro datacenter based dynamic resource estimation and pricing model for IOT. In: 2015 IEEE 29th international conference on advanced information networking and applications. IEEE. 2015. p. 687-94.

10. Akrivopoulos O, Zhu N, Amaxilatis D, Tselios C, Anagnostopoulos A, Chatzigiannakis I. A fog computing-oriented highly scalable iot framework for monitoring public educational buildings. In: 2018 IEEE international conference on communications (ICC). IEEE. 2018. p. 1-6.

11. Akrivopoulos O, Zhu N, Amaxilatis D, Tselios C, Anagnostopoulos A, Chatzigiannakis I. A fog computing-oriented, highly scalable iot framework for monitoring public educational buildings. In: IEEE international conference on communications (ICC). IEEE. 2018. p. 1-6.

12. Parikh S, Dave D, Patel R, Doshi N. Security and privacy issues in cloud, fog and edge computing. Proc Comput Sci. 2019;160:734-9

13. Abdel-Basset M, Manogaran G, Mohamed M, Rushdy E. Internet of things in smart education environment: supportive framework in the decision-making process. Concurr Comput Pract Exp. 2019;31(10):e4515.

14. Pecori R. A virtual learning architecture enhanced by fog computing and big data streams. Future Internet. 2018;10(1):4.

15. Martins J, Branco F, Gonçalves R, Au-Yong-Oliveira M, Oliveira T, Naranjo-Zolotov M, Cruz-Jesus F. Assessing the success behind the use of education management information systems in higher education. Telemat Inf. 2019;38:182-93

16. Jones KM. Learning analytics and higher education: a proposed model for establishing informed consent mechanisms to promote student privacy and autonomy. Int J Educ Technol High Educ. 2019;16(1):24.

17. Al Faruque MA, Vatanparvar K. Energy management-as-a-service over fog computing platform. IEEE Internet Things J. 2015;3(2):161-9.

18. Preden JS, Tammemäe K, Jantsch A, Leier M, Riid A, Calis E. The benefits of self-awareness and attention in fog and mist computing. Computer. 2015;48(7):37-45.

19. Okafor KC, Achumba IE, Chukwudebe GA, Ononiwu GC. Leveraging fog computing for scalable loT datacenter using spine-leaf network topology. J. Electr. Comput. Eng. 2017. https://doi.org/10.1155/2017/2363240.

20. Al-Khafajiy M, Baker T, Al-Libawy H, Waraich A, Chalmers C, Alfandi O. Fog computing framework for Internet of Things applications. In: 2018 11th international conference on developments in eSystems engineering (DeSE). IEEE. 2018. p. 71-7.

21. Aldowah H, Rehman SU, Ghazal S, Umar IN. Internet of things in higher education: a study on future learning. J Phys Conf Ser. 2017:892(1):012017.

22. Chiang M, Zhang T. Fog and loT: an overview of research opportunities. IEEE Internet Things J. 2016:3(6):854-64

23. Liu Y, Fieldsend JE, Min G. A framework of fog computing: Architecture, challenges, and optimization. IEEE Access. 2017:5:25445-54.

24. Hu P, Dhelim S, Ning H, Qiu T. Survey on fog computing: architecture, key technologies, applications and open issues. J Netw Comput Appl. 2017:98:27-42.

25. Bellendorf J, Mann ZÁ. Classification of optimization problems in fog computing. Future Gener Comput Syst. 2020;107:158-76.

26. Alli AA, Alam MM. The fog cloud of things: a survey on concepts, architecture, standards, tools, and applications. Internet Things. 2020;9:100177.

27. Xu X, Fu S, Cai Q, Tian W, Liu W, Dou W, Sun X, Liu AX. Dynamic resource allocation for load balancing in fog environment. Wireless Commun. Mob. Comput. 2018. https://doi.org/10.1155/2018/6421607.

28. Bagheri M, Movahed SH. The effect of the internet of things (IoT) on education business model. In: 201612 th international conference on signal-image technology \& internet-based systems (SITIS). IEEE. 2016. p. 435-41.

29. Long P. Siemens G. Penetrating the fog: analytics in learning and education. Ital J Educ Technol. 2014:22(3):132-7.

30. Zolfaghari B, Srivastava G, Roy S, Nemati HR, Afghah F, Koshiba T, Rai BK, et al. Content delivery networks: state of the art, trends, and future roadmap. ACM Comput Surv (CSUR). 2020;53(2):1-34.

31. Khalil M, Shamsi Z, Khan FU, Shahzad MA. Cloud computing: scope for human development and inclination towards fog computing. In: 2019 IEEE 21st international conference on high performance computing and communications; IEEE 17th international conference on smart city; IEEE 5th international conference on data science and systems (HPCC/SmartCity/DSS). Zhangjiajie: IEEE; 10 Aug 2019. p. 2514-9.

32. Khan MA, Umer T, Khan SU, YU S, Rachedi A. IEEE access special section editorial: green cloud and fog computing: energy efficiency and sustainability aware infrastructures, protocols, and applications. IEEE Access. 2018 Mar 19;6:12280-3.

33. Fischer C, Pardos ZA, Baker RS, Williams JJ, Smyth P, Yu R, Warschauer M, et al. Mining big data in education: affordances and challenges. Rev Res Educ. 2020:44(1):130-60.

34. Alghamdi F, Mahfoudh S, Barnawi A. A novel fog computing based architecture to improve the performance in content delivery networks. Wirel. Commun. Mob. Comput. 2019. https://doi.org/10.1155/2019/7864094.

35. Nazarenko MA, Khronusova TV. Big data in modern higher education. Benefits and criticism. In: International conference quality management, transport and information security, information technologies (IT\&QM\&IS). IEEE. 2017. p. 676-79. 
36. Tang B, Chen Z, Hefferman G, Wei T, He H, Yang Q. A hierarchical distributed fog computing architecture for big data analysis in smart cities. In: Proceedings of the ASE BigData \& Sociallnformatics; 2015. p. 1-6.

37. Mahmud R, Kotagiri R, Buyya R. Fog computing: A taxonomy, survey and future directions. In: Internet of everything. Singapore: Springer; 2018. p. 103-130.

38. Ni J, Zhang K, Lin X, Shen XS. Securing fog computing for internet of things applications: challenges and solutions. IEEE Commun Surv Tutor. 2017;20(1):601-28.

39. Vaquero LM, Rodero-Merino L. Finding your way in the fog: towards a comprehensive definition of fog computing. ACM SIGCOMM Comput Commun Rev. 2014;44(5):27-32.

40. Bonomi F, Milito R, Natarajan P, Zhu J. Fog computing: a platform for internet of things and analytics. In: Big data and internet of things: a roadmap for smart environments. Cham: Springer; 2014. p. 169-86.

41. Banica L, Burtescu E, Enescu F. The impact of internet-of-things in higher education. Sci Bull Econ Sci. 2017;16(1):53-9.

42. Rathna S, Shanmugavalli V. A three-layer privacy preserving cloud storage based on computational intelligence in fog computing. 2018.

43. Atlam HF, Walters RJ, Wills GB. Fog computing and the internet of things: a review. Big Data Cogn Comput. 2018;2(2):10.

44. Javadzadeh G, Rahmani AM. Fog computing applications in smart cities: a systematic survey. Wirel Netw. 2020;26(2):1433-57.

45. Tripathi G, Haq ZA. Big data analytics for industry oriented education system: an evolution of sustainable education model. In: Proceedings of ICETIT 2019. Cham: Springer; 2020. p. 647-53.

46. Arora JB, Kaushik S. IOT in education: a future of sustainable learning. In: Handbook of research on the internet of things applications in robotics and automation. IGI Global. 2020. p. 300-17.

47. Basir R, Qaisar S, Ali M, Aldwairi M, Ashraf MI, Mahmood A, Gidlund M. Fog computing enabling industrial internet of things: state-of-the-art and research challenges. Sensors. 2019;19(21):4807.

48. Tsai WT, Sun X, Balasooriya J. Service-oriented cloud computing architecture. In: 2010 seventh international conference on information technology: new generations. Las Vegas: IEEE; 12-14 Apr 2010. p. 684-689.

49. Zhamanov A, Sakhiyeva Z, Suliyev R, Kaldykulova Z. IoT smart campus review and implementation of IoT applications into education process of university. In: 13th international conference on electronics, computer and computation (ICECCO). IEEE. 2017. p. 1-4.

50. Barik RK, Lenka RK, Simha NVR, Dubey H, Mankodiya K. Fog computing based SDI framework for mineral resources information infrastructure management in India. 2017. arXiv:1712.09282.

51. Amor AB, Abid M, Meddeb A. Secure fog-based e-learning scheme. IEEE Access. 2020;8:31920-33.

52. Amaxilatis D, Akrivopoulos O, Chatzigiannakis I, Tselios C. Enabling stream processing for people-centric loT based on the fog computing paradigm. In: 22nd IEEE international conference on emerging technologies and factory automation (ETFA). IEEE. 2017. p. 1-8.

53. Stoica M, Mircea M, Ghilic-Micu B, Uscatu CR. From a smart education environment to an eco-school through fog \& cloud computing in loT context. Informatica Economica. 2018;22(4):5-14.

54. Bonomi F, Milito R, Zhu J, Addepalli S. Fog computing and its role in the internet of things. In: Proceedings of the first edition of the MCC workshop on mobile cloud computing. 2012. p. 13-6.

55. Neagu IM. Sustainable smart cities: a fog computing framework for a smart urban transport network. Studia Universitatis "Vasile Goldis" Arad-Economics Ser. 2018;28(4): 68-80.

56. Ni J, Zhang K, Yu Y, Lin X, Shen XS. Providing task allocation and secure deduplication for mobile crowdsensing via fog computing. IEEE Trans Dependable Secure Comput. 2018;17(3):581-94. https://doi.org/10.1109/ TDSC.2018.2791432

57. Bhatt J, Bhatt A. IoT techniques to nurture education industry: scope \& opportunities. Int. J. Emerg. Technol. 2017:128-32.

58. Ramlowat DD, Pattanayak BK. Exploring the internet of things (IoT) in education: a review. In: Information systems design and intelligent applications. Singapore: Springer; 2019. p. 245-55.

59. Ciolacu MI, Binder L, Svasta P, Tache I, Stoichescu D. Education 4.0-jump to innovation with loT in higher education. In: IEEE 25th international symposium for design and technology in electronic packaging (SIITME). IEEE. 2019. p. 135-41.

60. Giustiniano D, Varshney A, Voigt T. Connecting battery-free loT tags using LED bulbs. In: Proceedings of the 17th ACM workshop on hot topics in networks. 2018. p. 99-105.

61. Elsaadany A, Soliman M. Experimental evaluation of Internet of Things in the educational environment. Int. J. Eng. Pedagog. 2017. https://doi.org/10.3991/IJEP.V7|3.7187.

62. Song F, Ai ZY, Li JJ, Pau G, Collotta M, You I, Zhang HK. Smart collaborative caching for information-centric loT in fog computing. Sensors. 2017;17(11):2512.

63. Assante D, Fornaro C. An educational iot-based indoor environment monitoring system. In: 2019 IEEE Global Engineering Education Conference (EDUCON). Dubai: IEEE; 2019. p. 1475-9.

64. Cai J, Qin B, Zheng F, Li S, Luo Y, Zhang J. Design and application of innovative teaching platform based on fog computing. In: 2018 2nd International conference on education innovation and social science (ICEISS 2018). Atlantis Press; 2018

65. Naha RK, Garg S, Georgakopoulos D, Jayaraman PP, Gao L, Xiang Y, Ranjan R. Fog computing: survey of trends, architectures, requirements, and research directions. IEEE Access. 2018;6:47980-8009.

66. Kumar V, Laghari AA, Karim S, Shakir M, Brohi AA. Comparison of fog computing \& cloud computing. Int J Math Sci Comput. 2019;1:31-41.

67. Kumar Y, Kaul S, Sood K. A comprehensive view of different computing techniques-a systematic detailed literature review. In: International conference on advances in engineering science management \& technology (ICAESMT)-2019. Dehradun, India: Uttaranchal University; 14 Mar 2019. 
68. Borthakur D, Dubey H, Constant N, Mahler L, Mankodiya K. Smart fog: fog computing framework for unsupervised clustering analytics in wearable internet of things. In: 2017 IEEE global conference on signal and information processing (GlobalSIP). IEEE. 2017. p. 472-76.

69. Naranjo PGV, Shojafar M, Vaca-Cardenas L, Canali C, Lancellotti R, Baccarelli E. Big data over SmartGrid-a fog computing perspective. In: Proceedings of the 24th international conference on software, telecommunications and computer networks (SoftCOM 2016), Split, Croatia (2016. p. 22-4.

70. Choudhari T, Moh M, Moh TS. Prioritized task scheduling in fog computing. In: Proceedings of the ACMSE 2018 conference. 2018. p. 1-8.

71. Mukherjee M, Matam R, Shu L, Maglaras L, Ferrag MA, Choudhury N, Kumar V. Security and privacy in fog computing: challenges. IEEE Access. 2017;5:19293-304.

72. Kim T. Cyber physical systems framework of edge-, fog-, and cloud-computing. In: Proceedings of the international conference on embedded systems, cyber-physical systems, and applications (ESCS). The steering committee of the world congress in computer science, computer engineering and applied computing (WorldComp). 2019. p. 10-14.

73. Chang C, Srirama SN, Buyya R. Indie fog: an efficient fog-computing infrastructure for the internet of things. Computer. 2017;50(9):92-8.

74. Mahmud R, Srirama SN, Ramamohanarao K, Buyya R. Quality of experience (QoE)-aware placement of applications in fog computing environments. J Parallel Distrib Comput. 2019;132:190-203.

75. Marquez J, Villanueva J, Solarte Z, Garcia A. IoT in education: integration of objects with virtual academic communities. In: New advances in information systems and technologies.Cham: Springer; 2016. p. 201-12.

76. Zhang G, Wang T, Wang G, Liu A, Jia W. Detection of hidden data attacks combined fog computing and trust evaluation method in sensor-cloud system. In: Concurrency and computation: practice and experience. 2018. p e5109.

77. Zhang P, Zhou M, Fortino G. Security and trust issues in fog computing: a survey. Future Gener Comput Syst. 2018;88:16-27.

78. Yousefpour A, Fung C, Nguyen T, Kadiyala K, Jalali F, Niakanlahiji A, Jue JP, et al. All one needs to know about fog computing and related edge computing paradigms. 2018.

79. Lu R, Heung K, Lashkari AH, Ghorbani AA. A lightweight privacy-preserving data aggregation scheme for fog computing-enhanced IoT. IEEE Access. 2017;5:3302-12.

80. Alrawais A, Alhothaily A, Hu C, Cheng X. Fog computing for the internet of things: security and privacy issues. IEEE Internet Comput. 2017;21(2):34-42

81. Lee K, Kim D, Ha D, Rajput U, Oh H. On security and privacy issues of fog computing supported internet of things environment. In: 6th international conference on the network of the future (NOF). IEEE. 2015. p. 1-3.

82. Liu X, Yang Y, Choo KK, Wang H. Security and privacy challenges for Internet-of-Things and fog computing. Wirel Commun Mob Comput. 2018. https://doi.org/10.1155/2018/9373961

83. Elmroth E, Leitner P, Schulte S, Venugopal S. Connecting fog and cloud computing. IEEE Cloud Comput. 2017:4(2):22-5.

84. Kiryakova G, Yordanova L, Angelova N. Can we make schools and universities smarter with the internet of things? TEM J. 2017;6(1):80.

85. Rauniyar A, Engelstad P, Feng B. Crowdsourcing-based disaster management using fog computing in internet of things paradigm. In: IEEE 2nd international conference on collaboration and internet computing (CIC). IEEE. 2016. p. 490-94.

86. Razouk W, Sgandurra D, Sakurai K. A new security middleware architecture based on fog computing and cloud to support loT constrained devices. In: Proceedings of the 1st international conference on internet of things and machine learning. 2017. p. 1-8.

87. Hussain F. Internet of things: Building blocks and business models. Springer International Publishing; 2017.

88. Dastjerdi AV, Gupta H, Calheiros RN, Ghosh SK, Buyya R. Fog computing: Principles, architectures, and applications. In: Internet of things. Morgan Kaufmann. 2016. p. 61-75.

89. Jadeja Y, Modi K. Cloud computing-concepts, architecture and challenges. In: International conference on computing, electronics and electrical technologies (ICCEET). IEEE. 2012. p. 877-80.

90. Saharan KP, Kumar A. Fog in comparison to cloud: a survey. Int. J. Comput. Appl. 2015;122(3):10-12. https://doi. org/10.5120/21679-4773.

91. Hong HJ, Tsai PH, Cheng AC, Uddin MYS, Venkatasubramanian N, Hsu CH. Supporting internet-of-things analytics in a fog computing platform. In: 2017 IEEE international conference on cloud computing technology and science (CloudCom). IEEE. 2017. p. 138-145.

92. Wang T, Zhou J, Chen X, Wang G, Liu A, Liu Y. A three-layer privacy preserving cloud storage scheme based on computational intelligence in fog computing. IEEE Trans Emerg Top Comput Intell. 2018;2(1):3-12.

93. Giaretta A, Dragoni N, Massacci F. Protecting the internet of things with security-by-contract and fog computing In: IEEE 5th world forum on internet of things (WF-IoT). IEEE. 2019. p. 1-6.

94. Sarkar S, Misra S. Theoretical modelling of fog computing: a green computing paradigm to support loT applications. let Netw. 2016;5(2):23-9.

95. Aljumah A, Ahanger TA. Fog computing and security issues: a review. In: 2018 7th international conference on computers communications and control (ICCCC). IEEE. 2018. p. 237-39.

96. Gul S, Asif M, Ahmad S, Yasir M, Majid M, Malik MSA, Arshad S. A survey on role of internet of things in education. IJCSNS. 2017;17(5):159.

97. Datta SK, Bonnet C, Haerri J. Fog computing architecture to enable consumer centric internet of things services In: International symposium on consumer electronics (ISCE). IEEE. 2015. p. 1-2.

98. Deshmukh UA, More SA. Fog computing: new approach in the world of cloud computing. Int J Innov Res Comput Commun Eng. 2016;4(9):16310-6.

99. Dolui K, Datta SK. Comparison of edge computing implementations: fog computing, cloudlet and mobile edge computing. In: 2017 global internet of things summit (GloTS). IEEE. 2017. p. 1-6. 
100. Jayapandian N, Pavithra S, Revathi B. Effective usage of online cloud computing in different scenario of education sector. In: International conference on innovations in information, embedded and communication systems (ICIIECS). IEEE. 2017. p. 1-4

101. Großmann, M., loannidis, C., \& Le, D. T. Applicability of serverless computing in fog computing environments for IOT scenarios. In: Proceedings of the 12th IEEE/ACM international conference on utility and cloud computing companion. 2019. p. 29-34.

102. Hosseinian-Far A, Ramachandran M, Slack CL. Emerging trends in cloud computing, big data, fog computing, loT and smart living. In: Technology for smart futures. Cham: Springer; 2018. p. 29-40.

103. Dubey H, Monteiro A, Constant N, Abtahi M, Borthakur D, Mahler L, Mankodiya K, et al. Fog computing in medical internet-of-things: architecture, implementation, and applications. In: Handbook of large-scale distributed computing in smart healthcare. Cham: Springer; 2017. p. 281-321.

104. Gia TN, Jiang M, Rahmani AM, Westerlund T, Liljeberg P, Tenhunen H. Fog computing in healthcare internet of things: a case study on ecg feature extraction. In: IEEE international conference on computer and information technology; ubiquitous computing and communications; dependable, autonomic and secure computing; pervasive intelligence and computing. IEEE. 2015. p. 356-63.

105. Yi S, Qin Z, Li Q. Security and privacy issues of fog computing: a survey. In: International conference on wireless algorithms, systems, and applications. Cham: Springer; p. 685-95.

106. Zhu ZT, Yu MH, Riezebos P. A research framework of smart education. Smart Learn Environ. 2016;3(1):4

107. Quercia D, Hailes S. Sybil attacks against mobile users: friends and foes to the rescue. In: Proceedings IEEE INFOCOM. IEEE. 2010. p. 1-5.

\section{Publisher's Note}

Springer Nature remains neutral with regard to jurisdictional claims in published maps and institutional affiliations.

\section{Submit your manuscript to a SpringerOpen ${ }^{\odot}$ journal and benefit from:}

- Convenient online submission

- Rigorous peer review

- Open access: articles freely available online

- High visibility within the field

Retaining the copyright to your article

Submit your next manuscript at $\gg$ springeropen.com 